\title{
Elastase and its physiological inhibitors in ARDS: what decides between inflammatory storm or dead calm?
}

\author{
P.M. Suter
}

The mechanisms involved in the development of acute lung injury (ALI) and acute respiratory distress syndrome (ARDS) have been clarified to a certain extent over the last 10 yrs. A number of serious underlying diseases such as trauma, severe pneumonia or sepsis initiate a cascade of cellular and biochemical inflammatory reactions within the lung parenchyma, leading to a marked increase in capillary permeability, pulmonary oedema and severe gas exchange disturbances. Neutrophil attraction and activation by mediators such as cytokines and their release of elastase and oxygen radicals are hallmarks of ARDS [1-4].

Neutrophil elastase is involved in several types of lung damage in humans, including some forms of emphysema, chronic bronchitis, cystic fibrosis and ARDS. An imbalance between the enzyme elastase and its natural inhibitors seems to play a key role in these diseases [5-7]. A "physiologic release" of antiproteinases in ARDS and subsequent neutralization of elastase is also well described $[4,8]$. In addition, experimental observations suggest that treatment with elastase inhibitors reduces lung injury caused by endotoxin [9].

The data reported by SALLENAVE et al. [10] in this issue indicate that there was an increase of elastase inhibitors in the bronchoalveolar lavage (BAL) fluid of patients at risk of developing ARDS, which appears to contradict the important role played by leukocyte elastase in this syndrome. Do these data merely reflect an excessive autoregulatory reaction? Is the BAL level of antiproteinases directly related to the amount of elastase liberated a short time before? Can an overshooting neutralization of elastase by itself cause tissue damage?

At this time, we do not have answers to all these questions; even worse, we do not really understand how the delicate balance between pro- and anti-inflammatory forces is regulated, nor how the beneficial and detrimental activities of the neutrophils are titrated in situations such as severe infection, sepsis or ARDS. In addition, the relevance of local versus systemic levels of elastase, its inhibitors and other mediators of lung injury and remodelling remain to be elucidated $[4,11,12]$.

The incidence of ARDS after trauma or sepsis varies widely in the reported series, but is never $>50 \%$. This suggests that in a major proportion of the patients, the inflammatory cascade does not lead to severe tissue injury and/or the pulmonary parenchymal reaction and dysfunc-

Correspondence: P.M. Suter, Division of Surgical Intensive Care, University Hospital of Geneva, Geneva, Switzerland. Fax: 41223827455. tion is aborted or prevented. The balance between elastases and antielastases, and the characteristics of their release, binding and inactivation are certainly of primordial importance for whether or not severe tissue injury develops. However, we are still far away from a good understanding of these mechanisms.

The study of SALLEnave et al. [10] helps to push our understanding a small step further. The conclusion drawn by the authors can certainly be supported by the presence in the BAL of increased levels of antiproteinases in the early phases of ARDS development, whereas it is more difficult to accept that this finding may offer therapeutic potential in these patients for reducing morbidity and mortality. However, the conclusions of the present work from Scotland are clearly supported by another clinical study from Southern England, suggesting that together with surfactant administration in ARDS "antiprotease therapy may improve therapeutic prospects" [13].

Despite these encouraging signals, more unravelling of the pathophysiology of acute respiratory distress syndrome must be achieved before these findings can result in therapeutic implications.

\section{References}

1. Weiland JE, Davis WB, Holter JF, Mohammed JR, Dorinsky PM, Gadek JE. Lung neutrophils in the adult respiratory distress syndrome. Am Rev Respir Dis 1986; 133: 218-225.

2. Idell S, Kucich U, Fein A, et al. Neutrophil elastasereleasing factors in bronchoalveolar lavage from patients with adult respiratory distress syndrome. Am Rev Respir Dis 1985; 132: 1098-1105.

3. Cochrane CG, Spragg RG, Revak SD, Cohen AB, McGuire WW. The presence of neutrophil elastase and evidence of oxidation activity in bronchoalveolar lavage fluid of patients with adult respiratory distress syndrome. Am Rev Respir Dis 1983; 127: S25-S27.

4. Suter PM, Suter S, Girardin E, Roux-Lombard P, Grau GE, Dayer JM. High bronchoalveolar levels of tumor necrosis factor and its inhibitors, interleukin-1, interferon and elastase in patients with ARDS after trauma, shock or sepsis. Am Rev Respir Dis 1992; 145: 1016-1022.

5. Laurell CB, Ericksson S. The electrophoretic alpha-1 globulin pattern of serum in alpha-1 antitrypsin deficiency. Scand J Clin Lab Invest 1963; 15: 132-140.

6. Birrer P, McElvaney NG, Rudeberg A, et al. Proteaseantiprotease imbalance in the lungs of children with cystic fibrosis. Am J Respir Crit Care Med 1994; 150: 207-213. 
7. Lee CT, Fein AM, Lippman M, Holtzman H, Kimbel P, Weinbaum G. Elastolytic activity in pulmonary lavage fluid from patients with adult respiratory distress syndrome. N Engl J Med 1981; 304: 192-196.

8. Wewers MD, Herzyk DJ, Gadek JE. Alveolar fluid neutrophil elastase activity in the adult respiratory distress syndrome is complexed to alpha-2 macroglobulin. J Clin Invest 1988; 82: 1260-1267.

9. Gossage JR, Kuratomi Y, Davidson JM, Lefferts PL, Snapper JR. Neutrophil elastase inhibitors, SC-37698 and SC-39026, reduce endotoxin-induced lung dysfunction in awake sheep. Am Rev Respir Dis 1993; 147: 1371-1379.

10. Sallenave J-M, Donnelly SC, Grant IS, Robertson C, Gauldie J, Haslett C. Secretory leukocyte proteinase in- hibitor is preferentially increased in patients with acute respiratory distress syndrome. Eur Respir J 1999; 13: 1029-1036.

11. Donnelly SC, MacGregor I, Zamani A, et al. Plasma elastase levels and the development of the adult respiratory distress syndrome. Am J Respir Crit Care Med 1995; 151: 1428-1433.

12. Ricou B, Nicod L, Lacraz S, Welgus HG, Suter PM, Dayer JM. Matrix metalloproteinases and TIMP in acute respiratory distress syndrome (ARDS). Am J Respir Crit Care Med 1996; 154: 346-352.

13. Baker CS, Evans TW, Randle BJ, Haslam PL. Damage to surfactant-specific protein in acute respiratory distress syndrome. Lancet 1999; 353: 1232-1237. 